Cite as : Mattle, S., Birrer, D., \& Elfering, A. (2020). Feasibility of Hypnosis on

Performance in Air Rifle Shooting Competition. International Journal of Clinical and Experimental Hypnosis, 68(4), 521-529. doi:10.1080/00207144.2020.1799655

\title{
FEASIBILITY OF HYPNOSIS ON PERFORMANCE IN AIR RIFLE SHOOTING COMPETITION
}

Sabrina Mattle ${ }^{\mathrm{a}}$, Daniel Birrer ${ }^{\mathrm{b}}$, and Achim Elfering ${ }^{\mathrm{a}}$

aUniversity of Bern, Faculty of Psychology, Switzerland

${ }^{b}$ Federal Office of Sport, Swiss Federal Institute of Sport, Magglingen, Switzerland

\section{Correspondence to:}

Sabrina Mattle

Meret Oppenheim Platz 1

$\mathrm{CH}-4053$ Basel

now@momentality.ch

+41(0)7645768 21 


\begin{abstract}
This study investigated the effect of a single hypnosis intervention on shooting performance in a 10meter air rifle competition. Eight shooting athletes from the Swiss national team participated in the experiment; an A-B-A single case study design was used, with two baseline measurements. The results suggest that for 3 athletes the hypnosis intervention had a small positive effect on their performance compared to all other measurements, 6 subjects had small improvements compared to one baseline measurement, and two subjects had a performance decrease. Data from the participants' subjective rating of the intervention effect and their satisfaction with it demonstrated feasibility and that all eight subjects experienced the hypnosis intervention as positive; moreover, they commented that they felt calmer, more focused, and self-confident when they began the competition. Therefore, it seems promising for shooting athletes to learn how to integrate hypnosis into their training regimens, but additional research is needed.
\end{abstract}


Depending on the specific demands of the respective sport, the intervention aim, and the athlete's individual history and preferences, different psychological interventions and techniques can be applied to regulate performance-relevant psychological processes and states (Birrer \& Morgan, 2010). The most frequently used interventions are visualization (imagery), self-talk, defining goals, and various forms of emotion regulation, including relaxation (Whelan, Mahoney, \& Meyers, 1991). In shooting sports, a recent meta-analytic review reported a moderate effect size for three studies $(S M D=1.35$, $90 \% \mathrm{Cl}=0.61-2.09$ ) of mindfulness-based interventions on shooting performance (Bühlmayer, Birrer, Röthlin, Faude, \& Donath, 2017).

To better understand the mechanism of shooting performance, Kredel and Hossner (2013) modelled a chain of different factors which affect each other and lead to the shooting result. The chain starts with psychological factors, which impact the athlete's respiration, heartbeat, and muscle tension. These are followed by the position of the body, the power of contact to the rifle, the position of the gun, the movement to the muzzle, and the relative position of the target point and to the muzzle at the very moment of the shot; it ends with the shooting result. Therefore, not only the correct technique, but also psychological factors have a significant impact on the shooting result; according to Kredel and Hossner (2013), the shooting sequence starts with them. An individual that wants to come closer to his/her optimal performance must be able to regulate his/her psychological processes and mental state.

Several studies have investigated sport performance after several hypnosis interventions or after a single hypnosis intervention. In controlled studies and single-case design studies hypnosis has been found to have positive effects on athletic performance in basketball $(N=5$, Pates, Cummings, \& Maynard, 2002; $N=3$, Pates, Maynard, \& Westbury, 2001; $N=24$, Schreiber, 1991) and in golf $(N=1$, Pates, 2013; $N=3$, Pates \& Maynard, 2000; $N=5$, Pates, Oliver, \& Maynard, 2001). Studies have also reported that hypnosis has a promising effect on performance in soccer $(N=1$, Barker \& Jones, 2008; $d=.71, N=59$, Barker, Jones, \& Greenlees, 2010) and badminton ( $N=4$, Pates \& Palmi, 2002). Furthermore, there are indications of an increase in performance due to hypnosis in archery $(N=1$, Robazza \& Bortoli, 1995), cricket ( $N=1$, Barker \& Jones, 2006), and weightlifting ( $N=32$, Howard \& Reardon, 1986) as well as in throwing accuracy unrelated to a specific sport ( $N=22$, Jalene \& Wulf, 2014). In contrast, some studies have reported no enhancement of sport performance through hypnosis in tennis $(N=90$, Greer \& Engs, 1986), fencing ( $N=33$, Wojcikiewicz \& Orlick, 1987), and boxing $(N=$ 1, Heyman, 1987). 
In previous studies about the effect of hypnosis on sport performance, the contents of the hypnosis interventions were different, so hypnosis may have different effects and explanations. In hypnosis interventions that had a positive effect on sport performance, suggestions for confidence (Barker \& Jones, 2006, 2008; Barker et al., 2010; Schreiber, 1991), composure (Barker \& Jones, 2006, 2008; Barker et al., 2010), concentration (Schreiber, 1991), throwing accuracy (Jalene \& Wulf, 2014), multisensory experience of best performance (Pates, 2013; Pates et al., 2002; Pates \& Maynard, 2000; Pates, Maynard et al., 2001; Pates, Oliver et al., 2001; Pates \& Palmi, 2002), body awareness, focus, and flow (Robazza \& Bortoli, 1995) have been used. Studies in which hypnosis interventions did not have a significant effect on sport performance suggested that athletes visualize specific movements (Greer \& Engs, 1986) and use posthypnotic suggestions for confidence and relaxation (Wojcikiewicz \& Orlick, 1987), such as suggestions for silencing crowd noise (Heyman, 1987).

Currently, very few studies have investigated the effect of hypnosis on performance in competitions (Pates, 2013; Pates et al., 2001). Likewise, no studies in shooting sports have investigated the effect of hypnosis on shooting performance. The present study aimed to explore the effect of hypnosis on performance in shooting sports under competition conditions.

The present study used suggestions to enhance sport performance in shooting sports by asking the subjects to mentally go through an optimal shooting performance by focusing on the individual aspects needed to achieve an optimal performance, such as reproducing the feeling after an optimal performance. It was assumed that this would increase the athlete's focus on the important individual aspects while shooting and increase the probability that the imagined optimal performance would actually occur. When these components are taken together, it is hypothesized that the shooting performance after a single hypnosis intervention is better than the shooting performance observed from the baseline measurements.

\section{Method}

\section{Subjects}

Eight athletes who were members of the Swiss Shooting national team, of which four were female and four were male (two of the males were part of the junior national team), volunteered to participate in the study. All data were collected at the Shooting Masters, which is a series of competitions in which the best shooters from Switzerland compete against each other. The Shooting Masters serves to compare the performances of subjects from different cadres, associations, and clubs. The eight 
subjects in this study participated in all of the Shooting Masters competitions that took place at the same location.

The eight subjects ranged in age between 18 and $33(M=24.4, S D=5.55)$. They trained between 10 and 42 hours per week $(M=21.0, S D=10.74)$ and had different main disciplines. For one subject, the main discipline was the $10 \mathrm{~m}$ air rifle, for five subjects the main discipline was the $50 \mathrm{~m}$ rifle three positions. Both the $10 \mathrm{~m}$ air rifle and the $50 \mathrm{~m}$ rifle three positions were the main disciplines for one subject, and one subject did not have a specific main discipline. The subjects had different experiences with mental interventions. All of them had done muscle relaxation and visualization at least once; seven of the eight subjects had experience with autogenic training, three had experience with mindfulness training, and two had experience with meditation. However, none of the eight subjects had indicated previous experience with hypnosis.

\section{Experimental Design}

The study is based on an experimental A-B-A single case study design in which baseline measurements $(A)$ took place before the hypnosis intervention $(B)$, with follow-up measurements $(A)$ afterwards. The baseline measurements include the performances of two competitions (baseline 1 and baseline 2), which took place two weeks apart. The mean of all the shooting performances of all the competitions since the beginning of 2017 (mean 2017), reported by the subjects, was used as the data in order to ensure that the baseline measurements were more representative of the athletes' actual performance level. Both the intervention and follow-up measurements included data from one competition. The intervention measurement took place one month after the second baseline measurement; the follow-up measurement took place one month after the intervention measurement.

\section{Dependent Variable: Shooting Performance}

In shooting sports, there is an immediate feedback after every shot in the form of a number ranging between 0 and 10.9; a higher number indicates a better performance. At the end of the competition, the results of all the shots are tallied to obtain the total score so that every single shot, as well as the total score, can be used for the analysis. Therefore, performance can be measured very precisely. In our study, the shooting results of the official competition registration served as the dependent variable.

Subjects' Subjective Ratings of the Intervention Effect and Satisfaction 
After the competition with the hypnosis intervention, the subjects completed a second online questionnaire. In this survey, the athletes were asked to rate whether they agreed or disagreed with a series of statements about the intervention (for example: "I could engage well in the mental intervention."; "I believe that this mental intervention had an effect on my performance.") and the competition (for example: "I could concentrate well during the competition."; "The competition went well for me.") using a five-point Likert ranking scale $(0=\mid$ disagree, $1=\mid$ partially disagree, 2 = neither, $3=$ I agree partially, and $4=$ I fully agree). Moreover, they were able to comment on the intervention and the competition by answering open-ended questions (such as: "What else is there to say about the mental intervention? Was something unusual, special, distracting, pleasant or surprising?").

The Hypnosis Intervention

In this study, the hypnosis intervention was introduced to the subjects as a mental intervention. In the study by Barker et al. (2010), an entire session was used to explain hypnosis and answer the participants questions to increase rapport. In order to avoid this additional effort, the present study used the more neutral term, mental intervention, when communicating with the subjects.

The hypnosis intervention, which is available as transcript as supplemental material online, was implemented by the first author, who is trained in hypnosis. The hypnosis intervention was carried out one hour before the start of the $10 \mathrm{~m}$ air rifle competition, and it was conducted just outside the shooting range with each subject, separately. The hypnosis intervention used in this study was developed by Signer-Fischer (2019) and is called Perceive achieved goals, look back and experience the path to success (p. 249-250)(Signer-Fischer, 2019). Overall, the intervention lasted 10-15 minutes, depending on the time the subjects needed for enumerate their points for an optimal competition. There were two reasons for the short intervention: the structure of the intervention itself and the short time intervals between the different disciplines at the competition.

Data Analysis

The total scores of the intervention measurements and the baseline measurements for all subjects (including the mean performance since the beginning of 2017, which was self-reported by the subjects) were compared. In addition, the qualitative data were analyzed to learn more about the experiences the subjects had with the hypnosis intervention and to investigate the possible influencing factors that could have distorted the effect of the intervention. 


\section{Results}

\section{Shooting Performance}

Five (subject 2, 3, 5, 7 and 8) out of eight had a better performance after the hypnosis intervention than their mean score of 2017. Six subjects (subject 2, 3, 4, 5, 7 and 8) were better than one baseline measurement and three subjects (subject 2, 7 and 8) had a better performance after the hypnosis intervention compared to both baseline measurements. These three subjects had their best performance after the hypnosis intervention compared to all measurements. Subject 2 and subject 8 were able to achieve a new personal best shooting performance. Subjects 1 and 6 , however, had decreased their performance after the hypnosis intervention. Compared to all other measurements, the performance after the intervention was the lowest.

\section{Subjective ratings of the intervention effect and satisfaction}

After the competition with the hypnosis intervention, the subjects completed an online questionnaire. Analyzing the answers to the statements concerning the intervention and the competition using the five-point Likert scale $(0=\mid$ disagree, 1 = I partially disagree, $2=$ neither, $3=\mid$ agree partially, and $4=$ I fully agree), the subjective answers of the subjects indicated that they were able to successfully engage in the intervention $(M=3.75, S D=.46)$ and they could imagine the images during the intervention $(M=3.88, S D=.35)$ very well. They believed that the intervention had a positive effect on them $(M=3.25, S D=.71)$ and five of the eight subjects stated that the intervention enabled them to shoot better $(M=2.63, S D=0.52)$ and six of the subjects felt that it helped to improve their performance at the competition $(M=2.88, S D=.64)$. Basically, they believed that, in general, mental interventions might have a very positive effect on athletic performance $(M=3.88, S D=.35)$.

In addition to the ratings, the subjects commented on the intervention and the competition. Their comments showed that all of them experienced the intervention as being positive. Even one of the subjects who had a decrease in performance, in comparison to the baseline performance, wrote: "Through the mental intervention, I became aware of where in the body the good feeling after a great competition is best felt." This subject also stated that he underwent some major technical changes, so he was not really able to estimate the exact influence of the mental intervention. The seven other subjects provided the following comments:

I was able to adjust well to the competition ... I set a personal record ... The intervention helped me to get on the right track. ... I had the feeling, that I could start the competition much more 
calmly than usual. For me it was a great experience, I will use it more and more in the future.... Very interesting. ... At the beginning I really had a good feeling. I was not afraid, but I didn't want to make the impossible possible. ... I was sent into the competition very positively and confidently. In recent weeks much has changed in my position. There were also changes in the sequence and tactics of the shooting. At the end of today's competition, I had the feeling that I had consolidated all this.

In summary, for all eight subjects the hypnosis intervention was a positive experience and they stated that it had a positive effect on them. There were no negative comments in the questionnaire. In the open-ended questions they commented that they felt calmer, more focused, and more confident when the competition began. The rankings show that they mostly believed that the intervention enabled them to shoot better and improve their performance in the competition.

\section{Discussion}

The results suggest that for 3 athletes the hypnosis intervention had a small positive effect on their performance in the competition in comparison to the baseline measurements, the follow-up measurement and even the mean of the year 2017. Differences between one baseline measurement and the intervention measurement were found for six of the eight subjects. Two subjects had a performance decrease after the hypnosis intervention in comparison to all other measurements. However, for one subject this decrease might be due to the technical changes made in his shooting technique just before the competition with the hypnosis intervention. In view of the fact that all these subjects are among the best sport shooters in Switzerland, it is not surprising that no large effects were found for the hypnosis intervention. It is very difficult to significantly improve a performance that is already very high and that has a top score limitation (score of 10.9). Nevertheless, two subjects were able to achieve a new best shooting performance under the experimental condition.

The analysis of the subjective evaluation confirmed the potential value that a short hypnosis session might have on shooting performance. The eight subjects perceived the intervention as being helpful, and most of them believed that the intervention had a positive effect on their shooting performance. As described by the subjects, it seems as if the hypnosis intervention put them in a more optimal state for the shooting competition, including enhanced calmness, concentration, and selfconfidence. 
This study has several limitations. First, the hypnosis intervention was named as a mental intervention towards the subjects. This had the aim to avoid possible negative prejudices against hypnosis, but the renaming could have biased the effects. In a next study the hypnosis intervention should be named as such to avoid possible inaccuracies. This could be done with a pre questionnaire on attitudes and knowledge about hypnosis. Second, the hypnotizability of the subjects was not evaluated. In future studies, care should be taken to ascertain the hypnotizability of the subjects and their attitude towards hypnosis itself. Third, the intervention may have been too brief. In future studies this should be improved by using validated hypnotic inductions.

The results of the present study suggest that a short 10-15-minute hypnosis intervention might lead to a small increase in shooting performance. Therefore, coaches and athletes might consider implementing hypnosis interventions, with regard to individual aspects, into their training plans and apply them regularly, especially before a competition. Nevertheless, scientific evidence for the positive effect of hypnosis on athletic performance remains scarce, so further research is needed.

\section{Acknowledgements}

We would like to express our gratitude to Dr. Ralf Kredel from the Institute of Sport Science at the University of Bern, who let us participate in the shooting project, and to Dino Tartaruga, who was part of this shooting project team. Mr. Tartaruga explained the world of shooting sports to us and supported us with data collection at the competitions. We would like to thank Susy Signer-Fischer from the Centre for Developmental and Personality Psychology (ZEPP) at the University of Basel, who supported us with her hypnosis expertise. In addition, we are immensely grateful to the eight athletes for their participation in this study, for their openness, the interesting feedback, and the post-study discussions. 


\section{References}

Barker, J. B., \& Jones, M. V. (2006). Using Hypnosis, Technique Refinement, and Self-Modeling to Enhance Self-Efficacy: A Case Study in Cricket. The Sport Psychologist, 20(1), 94-110. https://doi.org/10.1123/tsp.20.1.94

Barker, J. B., \& Jones, M. V. (2008). The Effects of Hypnosis on Self-Efficacy , Affect, and Soccer Performance : A Case Study. Clincal Sport Psychology, 2, 127-147.

Barker, J. B., Jones, M. V., \& Greenlees, I. (2010). Assessing the Immediate and Maintained Effects of Hypnosis on Self-Efficacy and Soccer Wall-Volley Performance. Journal of Sport \& Exercise Psychology, 32(2), 243-252. https://doi.org/10.1123/jsep.32.2.243

Birrer, D., \& Morgan, G. (2010). Psychological skills training as a way to enhance an athlete's performance in high-intensity sports. Scandinavian Journal of Medicine \& Science in Sports, 20 , 78-87. https://doi.org/10.1111/j.1600-0838.2010.01188.x

Bühlmayer, L., Birrer, D., Röthlin, P., Faude, O., \& Donath, L. (2017). Effects of mindfulness practice on performance-relevant parameters and performance outcomes in sports: A meta-analytical review. Sports Medicine, 47(11), 2309-2321. https://doi.org/10.1007/s40279-017-0752-9

Greer, H. S., \& Engs, R. (1986). Use of progressive relaxation and hypnosis to increase tennis skill $\begin{array}{llllll}\text { learning. Perceptual and Motor Skills, 63, } 161- & 162 .\end{array}$ https://doi.org/http://dx.doi.org/10.2466/pms.1986.63.1.161

Heyman, S. R. (1987). Research and interventions in sport psychology: Issues encountered in working with an amateur boxer. The Sport Psychologist, 1, 208-223.

Howard, W. L., \& Reardon, J. P. (1986). Changes in the Self Concept and Athletic Performance of Weight Lifters Through a Cognitive-Hypnotic Approach: An Empirical Study. American Journal of Clinical Hypnosis, 28(4), 248-257. https://doi.org/10.1080/ 00029157.1986.10402661

Jalene, S., \& Wulf, G. (2014). Brief Hypnotic Intervention Increases Throwing Accuracy. International Journal of Sports Science \& Coaching, 9(1), 199-206. https://doi.org/10.1260/1747-9541.9.1.199

Kredel, R., \& Hossner, E.-J. (2013). Präzisionsleistungen im Olympischen Luftgewehrschiessen. Unpublished project work. University of Berne, Switzerland.

Pates, J. (2013). The Effects of Hypnosis On An Elite Senior European Tour Golfer: A Single-Subject Design. The International Journal Of Clinical And Experimental Hypnosis, 61(2), 193-204. https://doi.org/10.1080/00207144.2013.753831 
Pates, J., Cummings, A., \& Maynard, I. (2002). The Effects of Hypnosis on Flow States and Three-Point Shooting Performance in Bastketball Players. The Sport Psychologist, 16(1), 34-47. https://doi.org/10.1123/tsp.16.1.34

Pates, J., \& Maynard, I. (2000). Effects of hypnosis on flow states and golf performance. Perceptual and Motor Skills, 91, 1057-1075. https://doi.org/http://dx.doi.org/ 10.2466/pms.2000.91.3f.1057

Pates, J., Maynard, I., \& Westbury, T. (2001). An Investigation into the Effects of Hypnosis on Basketball Performance. Journal of Applied Sport Psychology, 13(1), 84-102. https://doi.org/10.1080/10413200109339005

Pates, J., Oliver, R., \& Maynard, I. (2001). The Effects of Hypnosis on Flow States and Golf-Putting Performance. Journal of Applied Sport Psychology, 13(4), 341-354. https://doi.org/10.1080/104132001753226238

Pates, J., \& Palmi, J. (2002). The effects of hypnosis on flow states and performance. Journal of Excellence, 6, 48-62.

Robazza, C., \& Bortoli, L. (1995). A Case Study of Improved Performance in Archery Using Hypnosis. Perceptual and Motor Skills, 81(3), 1364-1366. https://doi.org/10.2466/pms.1995.81.3f.1364

Schreiber, E. H. (1991). Using Hypnosis to Improve Performance of College Basketball Players. Perceptual and Motor Skills, 72, 536-538. https://doi.org/10.2466/pms.1991.72.2.536

Signer-Fischer, S. (2019). Hypnotherapie - effizient und kreativ. Bewährte Rezepte für die tägliche Praxis. Heidelberg: Carl-Auer.

Whelan, J. P., Mahoney, M. J., \& Meyers, A. W. (1991). Performance enhancement in sport: A cognitive behavioral domain. Behavior Therapy, 22(3), 307-327. https://doi.org/10.1016/S00057894(05)80369-7

Wojcikiewicz, A., \& Orlick, T. (1987). The effects of post-hypnotic suggestion and relaxation with suggestion on competitive fencing anxiety and performance. International Journal of Sport Psychology, 18, 303-313. 